\title{
IMPLEMENTASI KEBIJAKAN PROGRAM PESERTA DIDIK CERDAS ISTIMEWA (PDCI) DENGAN MODEL SISTEM KREDIT SEMESTER (SKS) DI MTS NEGERI 2 KEDIRI
}

\author{
Dwi Cahyanti Wabula \\ Agis Suna Li Ajlillah \\ Mufarrihul Hazin \\ State Colleges of Islamic Studies Kediri
}

\begin{abstract}
One of the most phenomenal issues in the current education system is the package system, but the system is less aspirational when it comes to the fact that learners are essentially good compounds of ability, talent and interest. To fulfill the service, they will be conducted by organizing a program of intelligent learners with Semester credit system model. The aim of this research as an effort in providing effective, efficient, and maximal education services to the students ' diversity in order to make their achievements good, maximal and fast. This study uses a qualitative research approach to type case studies. Data collection techniques using interviews, observations and documentation. The results showed that PDCl program with SKS model has been implemented well. The program in planning starts from policy drafting, forming teams, organizing seminars, conducting selection of teachers and students, arranging work programs, and managing licensing by submitting proposals.
\end{abstract}

Keywords: PDCI Program, SKS model

\begin{abstract}
Abstrak: Salah satu isu dalam sistem pendidikan yang paling fenomenal saat ini yaitu sistem paket, namun sistem ini kurang aspiratif ketika menghadapi kenyataan bahwa peserta didik pada dasarnya majemuk baik kemampuan, bakat maupun minat. Untuk memenuhi pelayanan tersebut maka ditempuh dengan menyelenggarakan program Peserta Didik Cerdas Istimewa dengan model Sistem Kredit Semester. Tujuan penelitian ini sebagai upaya dalam memberikan layanan pendidikan yang efektif, efisien, dan maksimal terhadap kemajemukan peserta didik agar prestasinya dapat terekplorasi dengan baik, maksimal dan cepat. Penelitian ini menggunakan pendekatan penelitian kualitatif jenis studi kasus. Teknik pengumpulan data dengan menggunakan wawancara, observasi dan dokumentasi. Hasil penelitian menunjukkan bahwa program PDCI dengan model SKS telah dilaksanakan dengan baik. Program tersebut dalam perencanaannya dimulai dari penyusunan kebijakan, membentuk tim, mengadakan seminar, melakukan seleksi terhadap guru-guru dan peserta didik, menyusun program kerja, dan mengurus perizinan dengan mengajukan proposal.
\end{abstract}

Kata kunci: Program PDCl, model SKS

Percepatan arus globalisasi dewasa ini menuntut semua bidang kehidupan untuk menyesuaikan visi, misi, tujuan serta strateginya agar sesuai dengan kebutuhan dan tidak ketinggalan zaman. Demikian halnya dengan sistem pendidikan, sistem pendidikan nasional senantiasa harus dinilai dan dikembangkan sesuai dengan kebutuhan dan perkembangan yang terjadi baik ditingkat lokal, nasional, maupun global (Sonia, 2016). Penyelenggaraan pendidikan di Indonesia harus memperhatikan perbedaan kecerdasan, kecakapan, bakat, dan minat peserta didik.

UUD RI Tahun 1945 Pasal 31 menyebutkan bahwa " setiap warga negara berhak mendapatkan pendidikan." Amanat yang terkandung dalam ayat tersebut adalah mendapatkan pendidikan merupakan hak setiap individu tanpa memandang latar belakang maupun kondisi yang ada pada mereka. Kemudian pemerintah menerbitkan UU RI No. 20/2003 Tentang Sistem Pendidikan 
Nasional Pasal 5 ayat 4, menegaskan bahwa " warga negara yang memiliki potensi kecerdasan dan bakat istimewa berhak memperoleh pendidikan khusus."

Fenomena kemajemukan peserta didik ini seharusnya terlayani sesuai dengan kebutuhannya. Namun, sistem pengelolaan pembelajaran di Indonesia pada umumnya menggunakan sistem paket. Keseriusan pemerintah untuk dapat meningkatkan kualitas pendidikan di Indonesia dapat dilihat dari berbagai kebijakan yang telah dikeluarkan (Sutrisno, 2014). Sistem ini mengharuskan peserta didik menempuh sistem pembelajaran yang sama dalam menyelesaikan program belajarnya. "Rapid changes which occurred in working life, interpersonal relations, science and technology have increased the interest on life-long learning concept" (Walesska \& Díaz, 2010). Salah satu implementasi dari UU RI No. 20/2003 Tentang Sistem Pendidikan Nasional pasal 5 ayat 4 adalah penyelenggaraan program akselerasi (percepatan belajar). Namun, program akselerasi sudah dihapus oleh kementerian pendidikan dan kebudayaan (Kemendikbud) sejak tahun ajaran 2015-2016 karena terkait dengan diberlakukannya kurikulum 2013 dan diganti dengan Permendikbud No.158 Tahun 2014 tentang penyelenggaraan $\mathrm{PDCl}$ dengan sistem kredit semester (SKS).

Pada dasarnya PDCl sama dengan program akselerasi karena sama-sama dapat ditempuh dengan percepatan sesuai dengan kemampuan siswa. Hanya pada sistem kurikulum yang berbeda (akselerasi dengan diferensiasi KTSP, PDCI dengan model pembelajaran SKS) serta yang berbeda pada perekrutan siswa cerdas istimewa. Pada tahun sebelumnya akselerasi adalah siswa CIBI (Cerdas Istimewa dan Bakat Istimewa) namun sekarang PDCI hanya untuk peserta didik cerdas istimewa dengan ketentuan tertentu. Alasan penutupan program akselerasi adalah ketidakcukupan durasi waktu yang kurang dari 14-18 minggu sehingga percepatan waktu tidak dibenarkan. (Permendikbud, 59/2014). "Developing and teaching their course, plus providing a workshop to students are important" (Aiken \& Sandas, 2002).
"Learners need to learn and achieve at their own pace so that they continue to feel motivated and believe that they can make progress" (Mayhew, Wolniak, \& Pascarella, 2008).

Berdasarkan Permendikbud 158 Tahun 2014 tentang penyelenggaran sistem kredit semester (SKS), tidak akan terjadi ketimpangan pelayanan bagi peserta didik yang memiliki kecerdasan istimewa untuk menyelesaikan program studinya tanpa harus terhambat oleh temannya yang lain demikian pula peserta didik yang memiliki kelemahan dalam proses percepatan penyelesaaian program studinya, tidak akan terpaksa mengikuti pola belajar peserta didik yang memiliki kecerdasan lebih. Upaya ini dapat memenuhi pelayanan pendidikan yang adil dan efektif pada semua peserta didik (Muhlis, 2017). "Moreover, educators (in the broadest sense including not only teachers but also education theorists and policymakers) have always served a particular purpose or ideology" (Roche, 2017). Kebijakan pemerintah dalam pengembangan kurikulum model penyelenggaraan sistem kredit semester merupakan salah satu kebijakan yang harus mendapatkan perhatian khusus dari para praktisi pendidikan baik pada pendidikan tingkat dasar maupun tingkat menengah (Rostika, 2013).

MTS Negeri 2 Kediri berupaya untuk memenuhi pelayanan pendidikan sesuai dengan amanat Undang-undang Nomor 20 tahun 2003 sebagaimana telah disebutkan sebelumnya. Dalam hal ini MTS Negeri 2 Kediri menyelenggarakan pembelajaran dengan sistem kredit semester (SKS) yang mengacu pada Permendikbud No. 158 Tahun 2014 tentang Penyelenggaraan Sistem Kredit Semester Pada Pendidikan Dasar dan Pendidikan Menengah.

Sistem kredit semester (SKS) ini diselenggarakan melalui pengorganisasian pembelajaran variatif dan pengelolaan waktu belajar yang fleksibel. Menurut (Muhlis, 2017) Pengorganisasian pembelajaran variatif dilakukan melalui penyediaan unit-unit pembelajaran utuh setiap mata pelajaran yang dapat diikuti oleh peserta didik. Sedangkan pengelolaan waktu belajar yang fleksibel dilakukan melalui pengambilan beban belajar untuk 
Dwi Cahyanti Wabula, Agis Suna Li Ajlillah Mufarrihul Hazin, Implementasi Kebijakan Program Peserta Didik Cerdas Istimewa (Pdci) Dengan Model Sistem Kredit Semester (Sks) Di Mts Negeri 2 Kediri

unit-unit pembelajaran utuh setiap mata pelajaran oleh peserta didik sesuai dengan kecepatan belajar masing-masing. Model pembelajaran dengan Sistem Kredit Semester (SKS) ini dapat pula dikelola dalam bentuk pembelajaran yang berdiferensiasi bagi masing-masing kelompok peserta didik yang berbeda kecepatan belajarnya dan mempunyai kecerdasan istimewa.

Berdasarkan pada penjelasan di atas, bahwa MTS Negeri 2 Kediri berupaya memberikan layanan pendidikan yang efektif, efisien, dan maksimal terhadap kemajemukan peserta didik agar potensinya bisa terekplorasi dengan baik, maksimal, dan cepat. Hal ini tentunya dapat terlaksana dengan adanya dukungan dari berbagai pihak, terutama manajemen, sumber daya manusia, serta sarana dan prasarana yang cukup memadai. Oleh karena itu, penulis ingin memaparkan sebuah kebijakan tentang program Peserta Didik Cerdas Istimewa (PDCl) dengan model Sistem Kredit Semester (SKS) di MTS Negeri 2 Kediri yang terfokus pada implementasi sehingga diketahui karakteristik pengembangannya. Penelitian penting dilakukan mengingat tidak semua madrasah dapat menyelenggarakan pembelajaran dengan Sistem Kredit Semester (SKS), kecuali setelah memiliki izin operasional berupa Surat Keputusan Direktur Jenderal Pendidikan Islam tentang madrasah penyelenggara Sistem Kredit Semester (SKS).

Dalam teori kecerdasan yang disusun oleh Sternberg yang di dalamnya terdiri dari tiga bentuk yaitu akademik, praktik dan kreatif, ketiganya mempunyai status yang sama dalam membentuk cerdas istimewa. Menurut teori yang dinamakan dengan Triarchy ini menegaskan bahwa setiap individu mempunyai perbedaan kekuatan dari salah satu unsur dari tiga aspek pembentuk kecerdasan.

Menurut Hearne sebagaimana rumusan dari departemen penddikan Amerika memberikan penegasan bahwa siswa $\mathrm{Cl}$ adalah siswa yang diidentifikasi oleh tenaga profesional dan mempunyai kemampuan pencapaian kinerja tinggi. Adapun area kemampuan yang ditujukan oleh siswa $\mathrm{Cl}$, yaitu kemampuan kecerdasan umum, bakat akademik khusus, berpikir kreatif dan produktif, kemampuan kepemimpinan, kemampuan psikomotorik dan seni peran serta visual. (Supriyanto, 2012)

Faktor-faktor yang mempengaruhi implementasi kebijakan menurut meter, antara lain ukuran dasar dan tujuan kebijakan, sumber daya kebijakan komunikasi antara organisasi, dan kegiatan-kegiatan pelaksanaan, kondisi ekonomi, sosial politik dan kecenderungan pelaksana. Dalam melaksanakan tahap perencanaan ini, pemerintah harus memandang pendidikan ke depan dan memperhitungkan kemungkinankemungkinan yang akan terjadi di masa yang akan dating (Fajarini, 2014). Model kebijakan tersebut menggambarkan faktorfaktor yang berpengaruh pada pencapaian tujuan kebijakan, baik secara langsung maupun tidak langsung (Hasnawati, 2013). Hal ini berpengaruh pada manajemen pelaksanaan ditingkat sekolah, antara lain: kebijakan sekolah dalam hal pembiayaan, kondisi sarana dan prasarana pembelajaran, partisipasi siswa dalam pembelajaran dan ekstrakulikuler, serta partisipasi Orangtua (Aulia, n.d.). Belajar merupakan tindakan dan perilaku yang kompleks. Sebagai tindakan maka belajar hanya dialami oleh individu itu sendiri dan akan menjadi penentu terjadinya atau tidak terjadinya proses belajar (Hasanah et al., 2017). Pemerintah diharapkan diharapkan dapat meningkatkan kemajuan pendidikan bagi anak-anak dan meningkatkan kesadaran bagi orang tua akan pentingnya pendidikan (Ajat Sudrajat, 2011). Minat dan motivasi belajar anak bersumber dari lingkungan keluarga itu sendiri (Malik, 2016).

Program peserta didik cerdas istimewa (PDCl) adalah program percepatan belajar selama dua tahun atau empat semester yang diperuntukkan bagi siswa yang memiliki IQ minimal 130, bakat, minat, dan kecerdasan yang lebih jika dibanding dengan kelas reguler dan bina prestasi. Dalam proses pembelajarannya di kelas PDCI lebih cepat. Sehingga tidak jarang terdapat siswa yang sulit memahami materi, maka mereka harus bertanya kepada temannya tentang materi tersebut dan belajar bersama. Maka biasanya siswa 
PDCI pulang sore karena mereka belajar bersama dengan temannya mengenai materi yang belum dipahami tersebut (Hidayatulloh, 2016).

Menurut keputusan Direktur Jenderal Pendidikan Islam Tahun 2016 tentang petunjuk teknis penyelenggaraan Sistem Kredit Semester pada Madrasah Tsanawiyah bahwa konsep Sistem Kredit Semester adalah bentuk pengelenggaraan pendidikan yang peserta didiknya menentukan jumlah beban belajar dan mata pelajaran yang diikuti setiap semester pada satuan pendidikan sesuai dengan bakat, minat dan kemampuan atau kecepatan belajar. Indeks prestasi atau IP adalah nilai akhiran capaian pembelajaran peserta didik pada akhir semester yang menyangkut nilai kompetensi pengetahuan dan kompetensi keterampilan. "The relationship between technology and lifelong learning is becoming more important" (Bahc, 2018). Sebagaimana disebutkan bahwa "Participants in adult learning are mostly young adults, particularly in the case of formal education" (Rogers, 2018). Untuk memenuhi hak warga negara, pemerintah pusat dan pemerintah daerah wajib memberikan layanan dan kemudahan, serta menjamin terselenggaranya pendidikan yang bermutu bagi setiap warga negara tanpa diskriminasi (Yusta \& Pradata, 2015).

Dalam melaksanakan SKS berprinsip kepada: 1) Fleksibelitas, penyelenggaraan SKS harus Fleksibel dalam pilihan mata pelajaran dan waktu penyelesaian masa belajar yang memungkinkan peserta didik menentukan dan mengatur strategi belajar secara mandiri. 2) keunggulan, penyelenggaraan SKS memungkinkan peserta didik memperoleh kesempatan belajar dan mencapai tingkat kemampuan optimal sesuai dengan bakat, minat, dan kemampuan atau kecepatan belajar. 3) Maju berkelanjutan, penyelenggaraan SKS memungkinkan peserta didik dapat langsung mengikuti mata pelajaran atau program lebih lanjut tanpa terkendala oleh peserta didik lain. 4) keadilan, penyelenggaraan SKS memungkinkan peserta didik mendapatkan kesempatan untuk memperoleh perlakuan sesuai dengan kapasitas belajar yang dimiliki dan prestasi belajar yang dicapainya secara perseorangan.

Tujuan dalam menerapkan SKS yaitu: 1) untuk mengelola bentuk pembelajaran yang berdiferensiasi bagi masing-masing kelompok peserta didik yang berbeda kecepatan belajarnya. 2) memberikan layanan kepada peserta didik untuk menyelasaikan dan menjalani proses pendidikannya sesuai dengan bakat, minat, dan kemampuannya, terutama bagi peserta didik yang memiliki kemampuan di atas rata-rata. 3) sebagai bentuk pembelajaran yang berdiferensiasi bagi peserta didik secara individu maupun kelompok yang berbeda kecepatan belajarnya untuk memaksimalkan potensinya agar terlayani dengan baik dan tidak mengalami underachievement.

Pengambilan beban belajar dalam SKS memperhatikan indeks prestasi (IP) yang dicapai oleh peserta didik setiap semesternya dengan ketentuan sebagai berikut: 1) pengambilan beban belajar untuk semester 1 (satu) berdasarkan prestasi yang dicapai pada satuan pendidikan sebelumnya dengan memperhatikan salah satu atau beberapa aspek dokumen seperti nilai rapot, nilai ujian nasional nilai Ujian Akhir Sekolah/ Madrasah, prestasi olimpiade/ kompetisi, dan nilai tes masuk. Aspek tersebut dapat diperkuat dengan memperhatikan hasil psikotes. 2) pada semester berikutnya besaran beban belajar peserta didik berdasarkan IP pada semester sebelumnya dengan memperhatikan ketentuan dalam Permendikbud no. 158 tahun 2014, Permendikbud no. 53 tahun 2015, dan kriteria mata pelajaran di madrasah, adalah sebagai berikut: a) IP < 67 dapat mengambil beban belajar paling banyak 50 jam pelajaran, b) IP 67-83 dapat mengambil beban belajar paling banyak 58 jam pelajaran, c) IP 84-91 dapat mengambil beban belajar paling banyak 66 jam pelajaran, d) IP > 91 dapat mengambil beban belajar paling banyak 74 jam pelajaran (Juknis, 2016).

Penyelenggaraan program percepatan belajar perlu dilakukan berbagai macam persiapan, antara lain: 1) mengadakan konsultasi dan komunikasi intensif dengan sekolah-sekolah yang sudah menyelenggarakan lebih dahulu program 
Dwi Cahyanti Wabula, Agis Suna Li Ajlillah Mufarrihul Hazin, Implementasi Kebijakan Program Peserta Didik Cerdas Istimewa (Pdci) Dengan Model Sistem Kredit Semester (Sks) Di Mts Negeri 2 Kediri

tersebut, untuk mendapatkan berbagai informasi. 2) membentuk tim kecil program percepatan belajar di sekolah penyelenggara yang terdiri dari kepala sekolah, wakil kepala sekolah dan guruguru senior yang memiliki kepedulian dan perhatian untuk memberikan layanan bagi anak yang memiliki kemampuan dan kecerdasaan luar biasa. 3) memberikan pembekalan dan wawasan tentang program percepatan belajar dengan mengundang narasumber atau sekolah yang sudah menyelenggarakan program tersebut. 4) melakukan seleksi terhadap guru-guru yang akan mengajar pada program tersebut. 5) menyusun program kerja. 6) mengurus perizinan penyelenggaraan program tersebut (Nidak, 2015).

"The nature, form and social context of these significant learning experiences are examined, with a particular focus on empowerment and transformation" (Antikainen, 1998). Berdasar hal tersebut maka berikut adalah tahap-tahap penyelnggaraan SKS. Tahap-tahap yang dapat dilakukan dalam penyelenggaraan SKS adalah sebagai berikut: 1) sekolah mengajukan proposal permohonan izin secara tertulis dilengkapi dengan data dan informasi tentang ketersediaan sumber daya pendidikan (input siswa, kurikulum, tenaga kependidikan sarana prasarana, dana, manajemen sekolah, proses belajar mengajar, dan lingkungan sekolah). 2) kepala dinas pendidikan kabupaten/ kota meneliti proposal sesuai dengan kriteria yang telah ditetapkan yang diterbitkan oleh Direktorat Jendral Pendidikan Dasar dan Menengah Depdiknas. sekolah-sekolah yang memenuhi kriteria selanjutnya diberikan rekomendasi oleh Kepala Dinas Pendidikan Kabupaten/ Kota untuk kemudian diusulkan guna memperoleh surat keputusan (SK) sebagai sekolah penyelenggara program dari Kepala Dinas Pendidikan Provinsi.

Menurut Witheringthon 1952 (dalam Fattah 2012), berpendapat bahwa evaluasi adalah pernyataan bahwa sesuatu atau objek itu memiliki nilai atau tidak. Artinya, evaluasi adalah segala sesuatu yang berhubungan dengan kegiatan atau proses untuk menentukan nilai sesuatu. Evaluasi merupakan proses untuk mendeskripsikan nilai dan makna. Berdasarkan beberapa rumusan tentang evaluasi dapat disimpulkan bahwa evaluasi adalah proses yang sistematis dan berkelanjutan untuk menentukan kualitas (nilai dan arti atau makna) dari sesuatu berdasarkan pertimbangan kriteria dan indikator tertentu dalam rangka membuat keputusan.

\section{METODE}

Metode yang digunakan dalam penelitian ini yaitu melalui pendekatan penelitian kualitatif dengan jenis studi kasus. Objek yang diteliti adalah MTS Negeri 2 Kediri yang terletak di Jalan Sunan Ampel No. 12, Ngronggo, Kecamatan Kota, Kota Kediri, Jawa timur. Peneliti menggunakan teknik wawancara, observasi, dan dokumentasi. Untuk wawancara dilakukan secara langsung terhadap wakil kepala sekolah, wali murid, dan murid. Analisis data yang digunakan yaitu mengumpulkan data, kondensasi data penyajian data, dan penarikan kesimpulan. Data yang diperoleh telah melalui tahap keabsahan data dengan adanaya tringulasi dan diskusi teman sejawat.

\section{HASIL DAN PEMBAHASAN}

Berdasarkan penelitian yang telah dilakukan di MTS Negeri 2 Kediri, maka implementasi kebijakan program peserta didik cerdas istimewa (PDCl) dengan model sistem kredit semester (SKS) dapat dilihat hasilnya sebagai berikut:

\section{Perencanaan Program PDCI Model SKS}

Perencanaan kebijakan program PDCl dengan model SKS di MTS Negeri 2 Kediri antara lain: 1) membentuk tim pengelola kebijakan program PDCl dengan model SKS yang terdiri dari kepala sekolah, wakil kepala sekolah, para guru dan masyarakat pendidikan, 2) melakukan kegiatan seminar, workshop dan kegiatan-kegiatan lainnya, 3) menentukan guru yang mengajar program PDCl melalui seleksi guru yang telah ada beserta rencana pengembangannya 4) menetapkan prosedur seleksi peserta didik yang memiliki IQ di atas 130, setelah siswa diterima nilai mata pelajaran minimal 90 
untuk semua mata pelajaran, 5) menyusun program kerja, 6) madrasah mengajukan proposal permohonan izin secara tertulis dilengkapi dengan data dan informasi tenteng ketersediaan sumber daya pendidikan (input siswa, kurikulum, tenaga kependidikan, sarana prasarana, dana, manajemen sekolah, proses belajar mengajar, dan lingkungan sekolah).

Paparan data di atas sesuai dengan pendapat Nidak (2015) bahwa penyelenggaraan program percepatan belajar perlu dilakukan berbagai macam persiapan, antara lain: 1) mengadakan konsultasi dan komunikasi intensif dengan sekolah-sekolah yang sudah menyelenggarakan lebih dahulu program tersebut, untuk mendapatkan berbagai informasi. 2) membentuk tim kecil program percepatan belajar di sekolah penyelenggara yang terdiri dari kepala sekolah, wakil kepala sekolah dan guruguru senior yang memiliki kepedulian dan perhatian untuk memberikan layanan bagi anak yang memiliki kemampuan dan kecerdasaan luar biasa. 3) memberikan pembekalan dan wawasan tentang program percepatan belajar dengan mengundang narasumber atau sekolah yang sudah menyelenggarakan program tersebut. 4) melakukan seleksi terhadap guru-guru yang akan mengajar pada program tersebut. 5) menyusun program kerja. 6) mengurus perizinan penyelenggaraan program tersebut.

Data tersebut didukung oleh Hidayatulloh, bahwa Program peserta didik cerdas istimewa (PDCl) adalah program percepatan belajar selama dua tahun atau empat semester yang diperuntukkan bagi siswa yang memiliki IQ minimal 130, bakat, minat, dan kecerdasan yang lebih jika dibanding dengan kelas reguler dan bina prestasi. Data tersebut juga sesuai dengan Permendikbud no. 53 tahun 2015, dan kriteria mata pelajaran di madrasah, adalah sebagai berikut: 1) IP $<67$ dapat mengambil beban belajar paling banyak 50 jam pelajaran, 2) IP 67-83 dapat mengambil beban belajar paling banyak 58 jam pelajaran, 3) IP 84-91 dapat mengambil beban belajar paling banyak 66 jam pelajaran, 4) IP > 91 dapat mengambil beban belajar paling banyak 74 jam pelajaran.
Dari ketiga data di atas dapat disimpulkan bahwa dalam perencanaan program peserta didik cerdas istimewa (PDCl) dengan model sistem kredit semester (SKS) mulai dari penyusunan kebijakan, membentuk tim, mengadakan seminar, melakukan seleksi terhadap guruguru dan peserta didik, menyusun program kerja, dan mengurus perizinan dengan mengajukan proposal. Dalam penyeleksian siswa baru harus memiliki IQ di atas 130 . Setelah siswa diterima nilai rapornya minimal 90 untuk semua mata pelajaran.

\section{Implementasi Program PDCI Model SKS}

Implementasi program PDCl dengan model SKS di MTS Negeri 2 Kediri meliputi: 1) koordinasi dengan pihak-pihak terkait, antara lain dengan Permendikbud, Kemenag, kepala sekolah, guru-guru, psikolog dan orang tua peserta didik, 2) sosialisasi program $\mathrm{PDCl}$ yang dilakukan melalui surat edaran, maupun pemuatan informasi di website, 3) identifikasi dan seleksi peserta didik program $\mathrm{PDCl}$ melibatkan psikolog, surat pernyataan kesanggupan yang telah disetujui orang tua untuk mengikuti program $\mathrm{PDCl}$, 4) pelaksanaan kegiatan belajar mengajar dengan jumlah peserta didik 20 (dua puluh) dalam satu angkatan, bentuk penyelenggaraannya dengan model sistem kredit semester (SKS) yang ditempuh selama 4 (empat) semester dengan jumlah 71 SKS persemester dimana 1 (satu) SKS ditempuh dalam waktu 30 menit. Apabila nilainya tidak memenuhi standar bisa ditempuh dalam 5 (lima) semester atau 6 (enam) semester seperti kelas reguler, 5) mata pelajaran diprogramkan oleh sekolah.

Paparan data di atas bertentangan dengan pendapat Santoso (2015) bahwa Sistem Kredit Semester adalah sistem penyelenggaraan program pendidikan yang peserta didiknya menentukan sendiri beban belajar dan mata pelajaran yang diikuti setiap semester pada satuan pendidikan. beban belajar setiap mata pelajaran pada sistem kredit satu semester meliputi satu jam pembelajaran tatap muka, satu jam penugasan terstruktur, dan satu jam kegiatan mandiri tidak terstruktur.

Dari kedua data di atas dapat disimpulkan bahwa implementasi program PDCI dengan model SKS di MTS Negeri 2 
Dwi Cahyanti Wabula, Agis Suna Li Ajlillah Mufarrihul Hazin, Implementasi Kebijakan Program Peserta Didik Cerdas Istimewa (Pdci) Dengan Model Sistem Kredit Semester (Sks) Di Mts Negeri 2 Kediri

Kediri di programkan sekolah karena peserta didik masih belum bisa memilih dengan baik program yang akan ditempuh, sedangkan pendapat santoso itu berlaku bagi SMA atau mahasiswa yang sudah bisa memilih dengan baik mata pelajaran yang akan ditempuh.

\section{Dampak Program PDCI Model SKS}

Dampak positif adanya program PDCl dengan model SKS di MTS Negeri 2 Kediri yaitu: siswa dapat menyelesaikan sekolah lebih cepat, siswa tidak bosan, sesuai dengan kemauan siswa, lebih merasa dihargai, menarik minat masyarakat untuk menyekolahkan anaknya di sekolah tersebut, membentuk siswa-siwa yang berkualitas, dll.

Dampak negatif adanya program $\mathrm{PDCl}$ dengan model SKS di MTS Negeri 2 Kediri yaitu: apabila penyeleksiannya tidak ketat dapat mengganggu psikologi siswa, terdapat guru yang belum mengetahui program tersebut sehingga siswa merasa bosan karena cara mengajarnya disamakan dengan anak reguler, waktu istirahat berkurang, interaksi dengan teman di luar kelas berkurang, waktu untuk ekstrakurikuler berkurang, dll.

Paparan data di atas sesuai dengan pendapat Sonia (2016) bahwa dampak positif adanya program PDCl dengan model SKS bagi siswa yaitu siswa dapat menyelesaikan sekolah dan studi lebih cepat, siswa merasa lebih dihargai kemampuannya, daya tarik masyarakat karena adanya program unggulan, dll. Sedangkan dampak negatif adanya program PDCI dengan model SKS bagi siswa yaitu siswa mengalami prestasi underachiever jika terdapat kesalahan penyeleksian, sikap acuh tak acuh dan malas belajar apabila pengajaran kurang mengundang tantangan baginya, siswa merasa kurang dalam kegiatan sosial, waktu istirahat sangat kurang, dll.

Dari kedua data di atas dapat disimpulkan bahwa dampak positif dan dampak negatif sangat berpengaruh terhadap program PDCl dengan model SKS

\section{Evaluasi Program PDCI Model SKS}

Evaluasi program PDCl dengan model SKS di MTS Negeri 2 Kediri dilakukan secara periodik, dilaksanakan di awal, pertengahan dan akhir tahun pembelajaran, evaluasi penyelenggaraan program PDCl dilakukan oleh tim khusus yang dibentuk oleh Kementrian Agama Provinsi Jawa Timur, unsur-unsur yang dievaluasi meliputi: 1) persiapan penerimaan calon siswa baru program PDCI, 2) SDM yang meliputi tenaga kependidikan, 3) sarana prasarana yang meliputi ruang kelas, perpustakaan, laboratorium, media pembelajaran, asrama, dan sarana pendukung lainnya, 4) dana untuk mendukung penyelenggaraan program PDCl, 5) pelaksanaan pembelajaran, 6) manajemen penyelenggaraan program PDCl, 7) prestasi siswa.

Menurut Hasnawati

(2013) menyatakan bahwa penyelenggaraan program PDCl akan terselenggara dengan baik apabila ada kesungguhan dari pengelola/ penyelenggara madrasah. Selain itu, keterlibatan secara aktif dari berbagai pihak yang berkepentingan, yaitu Kementerian Agama Kabupaten/ KotaProvinsi-Pusat, dan pemangku kepentingan (stakeholder) sangat dibutuhkan.

Dari kedua data di atas dapat disimpulkan bahwa evaluasi program $\mathrm{PDCl}$ dengan model SKS dilakukan secara periodik di awal, pertengahan dan akhir tahun pembelajaran. Evaluasinya dilakukan oleh tim khusus yang bersungguh-sungguh dalam mengelola madrasah agar program tersebut terselenggara dengan baik.

\section{KESIMPULAN}

1. Perencanaan program PDCl dengan model SKS di MTS Negeri 2 Kediri, mulai dari penyusunan kebijakan, membentuk tim, mengadakan seminar, melakukan seleksi terhadap guru-guru dan peserta didik, menyusun program kerja, dan mengurus perizinan dengan mengajukan proposal.

2. Implementasi program PDCl dengan model SKS di MTS Negeri 2 Kediri di programkan sekolah karena peserta didik masih belum bisa memilih dengan baik program yang akan ditempuh. 
3. Dampak positif dan dampak negatif sangat berpengaruh terhadap program PDCl dengan model SKS di MTS Negeri 2 Kediri.

4. Evaluasi program $\mathrm{PDCl}$ dengan model SKS di MTS Negeri 2 Kediri dilaksanakan di awal, pertengahan dan akhir tahun pembelajaran. Evaluasinya dilakukan oleh tim khusus yang bersungguh-sungguh dalam mengelola madrasah agar program tersebut terselenggara dengan baik.

\section{SARAN}

1. Program PDCI dengan model SKS harus diperketat sesuai dengan kemampuan siswa.

2. Sekolah seharusnya membuat kegiatan di Ma'had agar peserta didik cerdas istimewa tidak jenuh

3. Seharusnya ada sosialisasi kepada seluruh warga sekolah agar seluruh warga sekolah dapat mengetahui program PDCl dengan model SKS.

\section{DAFTAR RUJUKAN}

Aiken, R. M., \& Sandas, C. (2002). Using case studies to promote life-long learning. https://doi.org/10.1007/9780-387-35615-0

Ajat Sudrajat. (2011). Mengapa Pendidikan Karakter? Jurnal Pendidikan Karakter, 1(1), 47-58. Retrieved from https://journal.uny.ac.id/index.php/jpk a/article/view/1316/1094

Antikainen, A. R. I. (1998). BETWEEN STRUCTURE AND SUBJECTIVITY: LIFE-HISTORIES AND LIFELONG LEARNING T. Th. 44, 215-234.

Aulia, S. (n.d.). Desentralisasi Kebijakan Pendidikan ( Studi Tentang Pelaksanaan Wajib Belajar 12 Tahun Di Kota Surabaya Pada Tingkat Pendidikan Menengah dan Kejuruan ). 204-216.

HidAyatulloh, Syarifuddin. "Studi Implementasi Model Pembelajaran Akselerasi (Studi Kasus di Kelas Peserta Didik Cerdas Istimewa (PDCI) MAN 2 Ponorogo)". Skripsi tidak diterbitkan. Ponorogo: STAIN Ponorogo, 2016.

Bahc, N. M. (2018). Strategy for lifelong learning in vocational schools of tourism education. 43-58. https://doi.org/10.1007/s11135-0170586-4

Fajarini, U. (2014). Peranan Kearifan Lokal Dalam Pendidikan Karakter. SOSIO DIDAKTIKA: Social Science Education Journal, 1(2). https://doi.org/10.15408/sd.v1i2.1225

Hasanah, Y. M., Safruddin, C., Jabar, A., Pauh, T., Yogyakarta, U. N., Hasanah, Y. M., ... Yogyakarta, U. N. (2017). Jurnal Akuntabilitas Manajemen Pendidikan Online: http://journal.uny.ac.id/index.php/jam p Jurnal Akuntabilitas Manajemen Pendidikan Pendahuluan Pendidikan merupakan hal paling penting dan investasi masa yang akan da- tang dalam suatu negara. Pendidikan . 5(2), 228-239.

Keputusan Direktur Jenderal Pendidikan Islam Tahun 2016 tentang petunjuk teknis penyelenggaraan Sistem Kredit Semester pada Madrasah Tsanawiyah.

Mayhew, M. J., Wolniak, ÆE. G. C., \& Pascarella, ÆE. E. T. (2008). How Educational Practices Affect the Development of Life-long Learning Orientations in Traditionally-aged Undergraduate Students. 337-356. https://doi.org/10.1007/s11162-0079081-4

Muhlis, Achmad. "Pengembangan Pembelajaran dengan Sistem Kredit Semester di MTS Negeri Sumber Bungur Pamekasan". Nuansa, (2017), Vol. 14: 139-184.

Nidak, Khoiru. "Implementasi Pembelajaran Bahasa Arab pada Program Akselerasi di MAN 2 Tulungagung" Jurnal Realita, (2015), Vol. 13: 173-186.

HasNawati, Indah. "Implementasi Kebijakan Program Akselerasi di Kantor Wilayah Kementerian Agama Provinsi Jawa Timur". Jurnal 
Dwi Cahyanti Wabula, Agis Suna Li Ajlillah Mufarrihul Hazin, Implementasi Kebijakan Program Peserta Didik Cerdas Istimewa (Pdci) Dengan Model Sistem Kredit Semester (Sks) Di Mts Negeri 2 Kediri

Pendidikan Humaniora, (2013), Vol. 1: 150-158.

Nomor, V., Menyelesaikan, U., Wajar, P., \& Pendidikan, J. (2016). Jurnal Pendidikan dan Pemberdayaan Masyarakat camatan Tolangohula Kabupaten Gorontalo. 3(4), 38-47.

Roche, S. (2017). the value ( and values ) of lifelong learning. International Review of Education, 63(5), 623629. https://doi.org/10.1007/s11159017-9666-X

Rogers, A. (2018). Adult learning in modern societies: An international comparison from a life-course perspective. International Review of Education, 64(6), 865-866. https://doi.org/10.1007/s11159-0189741-y

Rostika, D. (2013). DENGAN SISTEM KREDIT SEMESTER.

Sutrisno, E. (2014). Motivasi Kerja, Sertifikasi , Kesejahteraan. 3(02), 148-155.

Permendikbud 158 Tahun 2014 tentang penyelenggaran sistem kredit semester (SKS)

Santoso, Arfie Bayu. "Pendidikan Berbasis SKS dalam Meningkatkan Prestasi Akademik Siswa Kelas SCI (Siswa Cerdas Istimewa)". Tesis tidak diterbitkan. Yogyakarta: UIN Sunan Kalijaga, 2015.

Sonia, Bur Rahmi. "Implementasi Kebijakan Program Peserta Didik Cerdas Istimewa (PDCI) dengan Model Sistem Kredit Semester (SKS) di Madrasah Aliyah Negeri Ngawi" (Tesis Tidak Diterbitkn, Yogyakarta: UIN Sunan Kalijaga, 2016.

Supriyanto, Eko. Pengembangan Kurikulum Pendidikan Cerdas Istimewa. Yogyakarta: Pustaka Pelajar, 2012.

Undang-Undang Republik Indonesia No. 20/2003 Tentang Sistem Pendidikan Nasional Pasal 5 ayat 4.

Walesska, M., \& Díaz, S. (2010). An approach of marketing relationship graduate - University for universities configuration as life long learning centres: an application to the University of Valencia. 191-193. https://doi.org/10.1007/s12208-0100048-3

Yusta, T., \& Pradata, W. (2015). EVALUSI PROGRAM WAJIB BELAJAR 12 TAHUN PADA MASYRAKAT MISKIN DI KELURAHAN WONOKUSUMO KECAMATAN SEMAMPIR. 3, 176185. 